\title{
Counteractive Measures for the Tribulations Faced by Intermediate Students of Selected Colleges of Lucknow, While Teaching and Learning English
}

\author{
Mohammad Owais Khan \\ Department of English, Najran University, Najran, KSA
}

\begin{abstract}
The present study attempts to highlight the issues related to the Tribulations and Counteractive measures for teaching and learning English to Intermediate students of Lucknow, Uttar Pradesh (UP), India. The language policy in intermediate college education emerged as a social and personal problem. The quality of English Language teaching in majority of Indian Intermediate Colleges presents a very appalling picture. Teachers' language proficiency, exposure to language and teaching materials is major concerns for quality English language learning. In reality intermediate students' situation in UP is very difficult. They don't have good opportunities as the big cities' students have. These students consider English as a subject not as a language. So they focus only on examination not on the learning. This is an area which needs proper investigation. This study and the remedial measures suggested at the end will hopefully help students and teachers in learning and teaching English easily and appropriately. The study will also be useful for teachers, scholars, course designers and material producers of English language teaching.
\end{abstract}

Index Terms - counteractive, tribulations, remedial measures and intermediate students

\section{INTRODUCTION}

There are two important factors with regard to the teaching of English to the Intermediate students:

(a) Mother tongue interference and

(b) The stark truth that the foreign language is the product of a communal, cultural and social habit.

The second factor is very often blatantly ignored by the teachers of English in India. The reason for this is the controversial claim that there is an independent variety of English, which should be called 'Indian English'. Hence meddling with English culture is of peripheral importance. This is a questionable premise and will only damage the progress of teaching an internationally acceptable variety of English used by the Indian students. The present study has, therefore, undertaken the task of analyzing the very crucial areas of spoken and written English- Pronunciation, speaking, spelling/vocabulary and grammar. It would be apt to highlight a few important concepts of language acquisition and a brief historical survey of ELT situation in India.

ELT Situation in India:

In the Indian context the introduction of English in India needs to be grasped fully in order to throw light on the priority of the skills in the teaching curriculum at different levels. We do agree with Bloomfield (1963) that "To work out the comparison between two languages, the descriptive data should be available." If a language is spoken in a large area, differences are bound to be there. Therein lies the difficulty of comparison by any researcher in this area.

The introduction of English in India can be surveyed through a clearly marked out set of phases from the 'fateful' advent of the East India Company on the Indian coast in the sixteenth century through the British occupation of India by the end of the eighteenth century or early nineteenth century when the sun never set on the global empire that the English had built up to fulfill their colonial ambition to the significant year of 1857 to 15 August 1947. When the East India Company came to India it was purely for commercial purposes, later it realized the tremendous potential of resources, which it could exploit for profit. As the Company expanded its commercial activities it needed people from the Sub-continent to act as interpreters between the Company and its Indian partners. These people needed to know English for effective mediation between the British businessmen and the Indian participants. Thus the earliest need for introducing English on to the Indian Sub-continent was to be at the oral level initially. Hence an artificial speech community, --- artificial because the most important component of interaction at the cross cultural levels was absent --consisting of the Indian and British business partners was necessitated. This brought into existence a sort of creolized English. As the business relationship and contact grew and got diversified the need for reading and writing was felt. This continued throughout the seventeenth and eighteenth centuries. In the absence of any authentically documented record of English teaching during this period one can surmise that there must have been a growing shift from the exclusively oral skill to reading and writing as well. No deliberate attempts were made during this period by the British 
to start any systematic schooling in English. Side by side with the business and political dimension of the activities of East India Company we have an interesting phenomenon taking place behind the door. This was East India Company's import into India of missionaries along with the merchandise. These missionaries were devout Christians committed to the expansion of their religion in the Far East. It is they who started the teaching of English in the schools established in India and funded by the Christian zealots on the British isle and Europe. These schools were started in the far flung eastern border areas and in the relatively liberal minded and cosmopolitan towns like Calcutta, Bombay, and Madras, the centers of business in India. These schools aimed at imparting instructions to the have-nots as well as the elitist classes. The have-nots were tempted with dole-outs and better means of livelihood after education while the elitist class was interested in getting their children acquire the necessary skills in the English language for social prestige and opportunities for preferment in the wake of the almost imminent prospect of growing British influences.

The crucial decision about the teaching of English and the relative emphasis on the skills was to be taken when the British were in firm control of the rein of power in India. They needed two things: one, they wanted their domination over the Indian Sub-continent to be acceptable to people by way of creating facilities for secondary school education which was, in fact, a welfare stunt; secondly they needed man-power to assist them in their governance of such a huge country.

After Independence the Indian leaders gave considerable thoughts to the problem of teaching English as a foreign language, as well as using English as a medium of instruction in higher education. Because of the linguistic diversity of India, it was felt by the Constitution framers that English should be allowed to be used as the second official language of the administration for 15 years. However, at the expiry of the dead line the linguistic riots in Madras in 1965 compelled the government to amend the Constitution more than once to allow English as a subsidiary official language and medium of instruction at the University levels. The issue of the use of English as a medium of instruction in higher education was hotly debated by a number of Commissions appointed by the government from time to time. The Radha Krishnan University Education Commission (1948) recommended the use of English for the purpose of enabling students to read books in English and gain knowledge. The Kunjru Commission set up in 1955 by the University Grants Commission was categorically in favour of retaining English as the medium of instruction in higher education. The same was the opinion of G.C. Banerji Committee appointed by the University Grants Commission in 1960 to discuss the objectives of teaching English. The specific Report of the English Committee, 1965, recommended that the teaching of English be organized for the purpose of using it as a library language -- an obvious emphasis on the skill of reading only. The Kothari Commission appointed by the Government of India in 1964 had opined that "English will, for a long time to come, continue to be needed as a library language in the field of higher education." However, it was the Study Group, consisting of specialists' appointed by the Government of India in 1964 which recommended that the skills of listening and speaking be emphasized at both the secondary school and advanced levels.

The emphasis on reading at the cost of the skills of listening and speaking was because of the prevailing international scenario until the middle of the last century. International interaction was not growing at any faster speed than before. Hence, proficiency in oral communication in English was not considered pedagogically of paramount importance. This situation was not confined only to India but to the other parts of the world where English was taught as a foreign language.

There is no short-cut to suggest a remedy for ill equipped teachers. A teacher must realize that any living language is deeply rooted in the culture of the region or the country where it belongs. Teaching a language, therefore, is teaching the culture of the native speaker of the language. One banal example will suffice to substantiate our observation above. In English the terms of greeting 'good morning', 'good afternoon', 'good evening' and 'good night' are all related to time. In Hindi there is only one term Namaskara denoting the social value of humanity. These commonly encountered terms have their cultural bearings. When we communicate in writing, the words of the foreign language do not present much difficulty because in conventional orthography only segmental features of the language --- e.g. the spelling system --- can be shown. When these very words are spoken a host of cultural implications arise. Teachers' own sound grounding in the cross-cultural similarities and differences reflected in the language use is of great importance. Robert Lado has written a full-length book on Linguistics Across Culture (1957) in his attempt to explain that since the cultural content of a language is an integral component of its very being a foreign language, a teacher will do well therefore if the cultural similarities and differences are given due importance.

\section{LITERATURE REVIEW}

As we know that for research work we have to see the past studies to find out the research gap. To fulfill these gaps we went through a number of studies. A brief analytical review of the writings of recognized authors and of previous research studies substantiates that the researcher is quite well acquainted with the previous studies in the concerned field.

Indeed, review of the related literature provides the academic guidance to the researcher. The researcher had noticed that basically all these studies focused on five aspects of English language teaching-learning such as (a) Methodology of Teaching, (b) Communication Skills, (c) Examination and evaluation issues, (d) Teaching- Learning Problems Identification and (e) Teacher Competence and Attitude. The details of these studies are given below in the forth coming paragraphs: 
Maratab, Zeeshan, Romana, Sobia (2015) attempted to conduct their study on the "Pronunciation Difficulties of Urdu Speakers Learning British Accent". The Objectives of the study were: a. to explore the difficulties of the Urdu speakers learning accent. (b) to facilitate the Urdu speakers learning British accent by highlighting the issues and causes behind them. Tools: A questionnaire was conducted. Findings: Learning British accent for an Urdu speaker is not an easy task especially the absence of the native like environment makes it more difficult. British accent has its factors such as absence of proper connection between spellings and its pronunciation, very complex stress pattern, silent letters, multiple sounds of one letter etc. which makes learning tougher for Urdu speakers.

William, Raja \& Selvi, (2011) attempted to conduct their study on causes of problems in learning English as a second language as perceived by higher secondary students. The Objectives of the study were: (i) to identify the leading cause of problems in learning English as a second language. (ii) to find out the significant difference if any in the causes of problems in learning English in regard to sex, locality of school, optional subject, habit of reading English newspaper and habit of listening to English news. Tools: A questionnaire was conducted for the students. This study involved data collection through survey method. Recommendations: The government should often conduct in-service training to train the teachers to use English language in classrooms. They should try to bring reforms in the pattern of examination. Separate marks could also be allotted to test the spoken language of the students. Children are more successful when their parents are involved in their education.

Qudsiya. Hashmi (2016) attempted to conduct her study on a study of the "Difficulties in Learning of English Faced by Hindi and Urdu Medium Students of India and Indian Expatriates in Saudi Arabia." The Objectives of the study were: (i) to examine the use of English as a first, second and third language in school curriculum as defined by various agencies of the state apparatus. (ii) to examine the issues that might have been overlooked while designing the curriculum for the teaching of English in the non-English speaking world. (iii) to study the process of learning English in India against the backdrop of societal changes and other relevant factors. Tools: 1. Specifically designed assignments, quizzes and questionnaire to test the linguistic capabilities of learners. 2. Teachers questionnaire. Findings: The researcher finds teaching English very serious problem which has huge ramifications as far as the future of the students and our education system is concerned. We are all a part of a system that does not allow a child to think for himself. Not only is there no room for creativity and subjectivity, our teaching methodology focuses entirely on the quantity of education given in terms of time and books, but not on the quality of teaching. The focus is on the number of hours that a teacher is teaching, but not even remotely on the 'what' and the 'how' of the teaching process. While the student's attendance holds supreme importance, his/her interest and 'learning' is a matter of no concern. So long as we hold such a utilitarian and reductive approach to our method of education, the results will continue to be as dismal as they have been in the current research. Recommendations: Based on the results and conclusions, following are some of the recommendations: 1- Diagnostic analysis needs to be done by the concerned teachers of English to understand the problems, 2- A comparative analysis needs to be performed to deal with the teaching-learning situations, 3- A proper strategy needs to be evolved to cater to the needs of the bilingual learners of English.

P. Shrinivasalu. Reddy (2012), conducted a study on "Problems in Teaching and Learning English as a Second Language in India" The Objectives of the study were: (i) to improve the teaching practice (ii) to bring clarity in teaching concepts (ii) to co-ordinate the principles of teaching. Tools: A questionnaire was conducted. Findings: Some of the major findings of the study were lack of clear cut policy, lack of exposure to the language, non-availability of teaching learning material, lack of good teachers, lack of motivation, large classes and faulty examination system. Recommendations: The teachers have to gear up to meet the demands of the situation and successfully perform their duties. The objectives and needs of teaching are to be matched. The principles and methods of teaching should be coordinated to promote better standards of achievement.

Shruti Pal (2018) conducted a study on "Mother Tongue Influence on Spoken English." The Objectives of the study were: (i) to find out the English pronunciation problems faced by speakers of Hindi. (ii) to devise classroom suggestions to overcome the identified problems. Tools: Three kinds of tools were designed for the purpose of this study. a. questionnaire. b. pre-test tool. c. 50 teaching activities related to the identified problem were constructed and used in the classroom with the aim of helping learners improve their pronunciation. Findings: The data analysis helped identify and conclude: - The major pronunciation problem areas faced by speakers of Hindi were: 1. Fricative sounds such as /s/ /z/ / / / / z / 2. Plural markers 3. Consonant clusters 4. Vowel sounds which differed from the Hindi sound system and had varied spelling. The results of this study help us understand these factors and have implications for classroom planning and curriculum transaction. Recommendations: It is thus important to understand the factors affecting correct spoken English. Teachers in the Hindi speaking belt should help their learners work on their pronunciation skills by planning appropriate classroom activity and instruction.

Arnab Chaudhary and Jayanta Mete (2017) tried to attempt their study on the topic "A Study on English Teaching Learning Method in a Hindi Medium School in Nadia District of West Bengal." The Objectives of the study were: (i) to illustrate ways in which a bias in favor of English medium poses serious problems in accessing knowledge. (ii) How do we empower a learner to become an active creator of knowledge and to acquire and develop new skills? Tools: 1. questionnaire. 2. A sample survey of 52 students in a Hindi medium school. Findings: a. A majority of Hindi medium students affirmed that they felt disadvantaged by pursuing education in Hindi medium. b. A greater percentage of students in Hindi were more confident in expressing their understanding in their own words as compared to English 
medium students. c. A significant proportion of Hindi medium students had difficulty in accessing English medium resources. Recommendations:- For redefining education and to make them active agents in creating knowledge for change, it is important to deepen awareness about ways in which language governs the learning -teaching process. There should be a serious need of knowledge laboratories or institutional arrangements where teachers can upgrade their abilities and be equipped to deal with the needs of the students. The approach of developing text books for students also needs to be changed.

Maninder Kaur Kainth and Mahesh Kumar (2014) attempted to conduct a study on "Teaching English Language at Engineering and Technology Institutes In India: Problems And Remedies" Objectives of the study were: a. to trace the problem faced by both teachers and students in the English teaching and learning process at the undergraduate level in engineering institutes b. to present the contemporary situations in India with regard to English and suggesting remedies for it. Tools:- A survey method was used with the teachers as a tool to find out the cause of the problem. Findings:--The study revealed that a. there is an urgent need to teach life skills and job-oriented English language skills b. the teachers should build confidence in students by playing the role of a facilitator c. the teachers should assess the present and future needs of the learners. Recommendations: a. there is an urgent need to teach English as a life skill which will help the students to be successful in living a productive life. b. there is an urgent need to teach engineering students joboriented English language skills. c. the teachers should customize their teaching methodology according to the need of the learners and should play the role of a facilitator rather than an instructor.

G. Vijay (2014) attempted to conduct his study on "Constraints of Teaching English in Engineering Colleges." Objectives of his study were: a. to make learners acquire all the four skills in both formal and informal contexts b. to make them acquire language skills by using e-materials and language lab components. Tools: He used a survey method with the teachers of Anna University Chennai. Findings:--His study revealed that a. teachers face a difficult task when students are not motivated to learn English. b. Teachers face challenges such as irrelevant syllabus, lack of motivation etc c. teachers need to continuously improve their communicative skills in English. Recommendations: a. teachers need to continuously improve their communicative skills in English. b. the teachers should openly face the challenge of irrelevant syllabus, heterogeneous background of students and lack of motivation. c. the syllabus content and the evaluation system should also be improved.

Priya Sasidharan (2012) attempted to conduct her study on "A Needs Based Approach to Teaching and Learning of English for Engineering Purposes.” Objectives of the study were: a. to assess the English language needs of Engineering colleges of Orissa b. To examine the existing English syllabus currently taught in the engineering colleges of Orissa and to ascertain how far they meet the students' communicative needs. c. to identify the academic and professional needs of engineering students at different engineering colleges in the Indian state of Orissa. Tools:--She conducted her study by a questionnaire based survey among students and teachers. Findings:-- The study indicates that engineering students need not only linguistic competence in English but also certain life skills and technical skills related to language learning. $b$. syllabus should be able to handle real life situations on completion of their engineering course. c. the syllabus of Communicative English course needs to be addressed immediately to improve the quality of ELT in the Engineering programs. Recommendations: a. to develop professional competence, the awareness of social and cultural aspects related to engineers' workplace can be exercised in the classroom by selecting authentic materials. b. the students should be provided facilities and guidance in developing technical English skills, with a proper orientation and practice they can develop a broad perspective to face future workplace needs. c. the teachers should give a lot of practice to students in lab classes, Power-point presentations, interview sessions, report writing, and group discussions.

\section{Methodology}

Significance of the Study: English is considered as a world language because of its immense ascendancy all over the world. At this stage, learning English is a kind of fashion. Most of the Indian students from rural areas think that English is the only source which can help them in getting good jobs, luxurious life, high status and prosperity in the society. They feel that if they will learn English, they will be successful person in the world. But when they hear anything in English they feel hesitant and nervous. In Indian government schools, English starts from $3^{\text {rd }}$ or $4^{\text {th }}$ standard. As the students come from rural areas for learning English they want to learn English through their mother tongue, so bilingual grammar translation methods are adopted in language classes. These methods don't help learners in learning English specially listening and speaking. It has been observed that in most of the intermediate colleges where medium of instruction is Hindi they offer English courses but listening and speaking practice is ignored. Moreover, this process minimizes the real learning activities as a whole. The concept of efficiency of a language teaching method depends mainly on five different components as mentioned below. (a) Aims and objectives of teaching, (b) Teaching materials (according to the level of the learners), (c) Testing \& Evaluation procedures, (d) Listening and speaking practice and (d) Teacher's/learner's motivation.

Further, all the above mentioned five components should be critically analyzed so that we can provide maximum benefits to learners. It is clearly visible that the first three modules i.e. aims and objective of teaching, teaching materials, testing and evaluative procedures function externally and the last two points operate internally. Thus, the interaction and the meaningful coordination between the teacher and the learner is, to a large extent dependent upon the 
sensible relationship between the aims of teaching, testing and evaluating techniques, the study material and practice of listening and speaking regularly.

\section{A. Statement of the Problem}

Identification of the Counteractive Measures of the Tribulations Faced by Intermediate Students of Selected Colleges of Lucknow, Uttar Pradesh, while Teaching and Learning English.

\section{B. Limitations of the Study}

The present study was delimited to the intermediate students and English teachers those who teach English at the Intermediate level in selected colleges of Lucknow. UP, India i.e. Babu Banarsi Daas College, Lucknow and Karamat Hussain P.G. Girls College, Lucknow.

\section{Choice of Informants}

The corpus of the data for analysis was selected from the Intermediate students of Babu Banarsi Daas College (BBDC), Lucknow and Karamat Hussain P.G. Girls College (KHGC), Lucknow. These students mostly come from the rural areas of Hindi and Urdu speaking regions. Hence selection of informants for the present study was felt to be more meaningful. These informants who had been speaking Hindi/Urdu as their first language were identified because they had some sort of uniformity in their speech utterances as well as diversity because of the regional differences of their previous schooling. Out of total 500 students, 107 students were keenly offered to respond to the questionnaires and take the question paper specially prepared for the purpose of collecting data for this research. Therefore, the investigator took 107 students as the informants of the study. As the strength of the students of Engineering and Education of both the two institutions varied to a greater extent, we did combined investigation for the purpose of the study. The details of both the Institutions under investigation were given as under:

We have provided questionnaire to 220 students in Karamat Hussain P.G. Girls College, Lucknow, only 44 students returned and in Babu Banarsi Daas University, Lucknow 280 questionnaire have been distributed and out of them only 63 students have returned the questionnaire. The details of the informants are shows in the following table \& Chart.1.

TABLE I

TABLE SHOWING DistRIBUTION OF INFORMANTS (STUDENTS)

\begin{tabular}{|c|l|c|c|c|c|c|}
\hline \multirow{2}{*}{ S.No. } & \multicolumn{1}{|c|}{ Name of the College } & \multirow{2}{*}{ Strength } & \multicolumn{3}{|c|}{ Informants Size } & \multicolumn{2}{c}{$\begin{array}{c}\text { Percentage of } \\
\text { Informants }\end{array}$} \\
\cline { 4 - 7 } & & & Boys & Girls & Total & \\
\hline 1. & Babu Banarsi Daas University, Lucknow. & 280 & 40 & 23 & 63 & $22.5 \%$ \\
\hline 2. & Karamat Hussain P.G. Girls College, Lucknow. & 220 & 0 & 44 & 44 & $20.59 \%$ \\
\hline 3. & Total & 500 & 40 & 67 & 107 & $21.04 \%$ \\
\hline
\end{tabular}

The number was deliberately limited not exceeding 107 students. The record of all the above informants and their particulars were maintained in the questionnaire.

\begin{tabular}{l} 
CHART NO. 1 OF TABLE 1 \\
SHOWING THE DISTRIBUTION OF INFORMANTS (STUDENTS) \\
\hline
\end{tabular}

\section{Choice of Material}

(i) In order to be able to grasp the violation or neglect of the socio-cultural component in an interactive speech act, a detailed questionnaire was prepared.

(ii) A sentence list including simple words, compound words and words involving functional shift of stress for analyzing the stress and intonation patterns of English.

(iii) A test of English language skills which measures informants' English level was prepared to investigate the oral and aural abilities of the informants. This test was consisted of Listening \& Speaking, Writing, Grammar \& Vocabulary and Pronunciation. 


\section{DATA ANALYSIS}

The corpus of the data contains editing, classifying and tabulating the statistics which was collected from the Intermediate students and English teachers those who teach English at the Intermediate Colleges of Lucknow, i.e. Babu Banarsi Daas college, Lucknow, and Karamat Hussain P.G. Girls College, Lucknow, through the management of various tools on the selected informants. Further, this arrangement also presents and illustrates certain modes which are helpful in the analysis of the gathered data. The data is analyzed by using the IBM SPSS Statistics 20 data editor which is a latest software to edit, classify, tabulate and analyze data. The "Data Analysis" discusses the meaning of suitable and dependable outcomes and the inter relationships among the outcomes.

\section{A. Analysis of Teachers' Questionnaire}

The first section of the Teachers' Questionnaire contained the general and demographic information of the sample of the teachers such as their age, educational qualification, experience and work load. In short, it is presented a brief profile of the sample of various aspects of the college teachers. The distribution of the sample of teachers by various segments such as gender, age, qualification, experience and weekly work load, is shown in the table below:

TABLE II

Distribution OF VARIOUS COMPONENTS OF TEACHERS' PROFILE BABU B ANARSi DAAS COLLEGE.

\begin{tabular}{|c|l|l|c|c|}
\hline S.No. & & No. of Teachers & Percentage \% \\
\hline \multirow{2}{*}{1} & \multirow{2}{*}{ Gender } & Compone & 6 & $54.54 \%$ \\
\cline { 3 - 5 } & & Female & 5 & $45.45 \%$ \\
\hline \multirow{2}{*}{2} & \multirow{2}{*}{ Age } & Below 29 & 4 & $36.36 \%$ \\
\cline { 3 - 5 } & & Above 30 & 7 & $63.63 \%$ \\
\hline \multirow{4}{*}{3} & \multirow{3}{*}{ Qualification } & Post Graduate & 11 & $100 \%$ \\
\cline { 3 - 5 } & & Pursuing Ph.D & 3 & $27.27 \%$ \\
\cline { 3 - 5 } & & Ph.D. & 4 & $36.36 \%$ \\
\cline { 3 - 5 } & & B.Ed/M.Ed. & 4 & $36.36 \%$ \\
\hline \multirow{2}{*}{4} & \multirow{2}{*}{ Experience } & Below 5 years & 8 & $27.72 \%$ \\
\cline { 3 - 5 } & & Above 10 years & 3 & $72.72 \%$ \\
\hline \multirow{2}{*}{5} & \multirow{2}{*}{ Weekly Work Load } & $16-18$ hours & 8 & $27.27 \%$ \\
\cline { 3 - 5 } & & $10-12$ hours & 3 & \\
\hline
\end{tabular}

All the teacher respondents in Babu Banarsi Daas University, Lucknow possess Masters Degree in English Literature. 4 of them possess the Ph.d. Degree, 4 of them have M.Ed. degree and 3 other teachers are pursuing their Ph.D. 8 out of 11 teachers $(72.72 \%)$ have got less than 05 years of their teaching experience at the U.G. level and the remaining 3 teachers $(27.27 \%$ ) have got experience of more than 10 years. Depending upon the strength of the college, 8 out of 11 teachers $(72.72 \%)$ have got the maximum work load of 18 to 20 hours per week. The remaining three of them $(27.27 \%)$ reported that they engage 10 to12 hours per week. The following graph No.4.1.2 shows the various components of teachers' profile and their numbers.

The following chart is showing the percentage \% of the teachers' profile of Babu Banarsi Daas University, Lucknow.

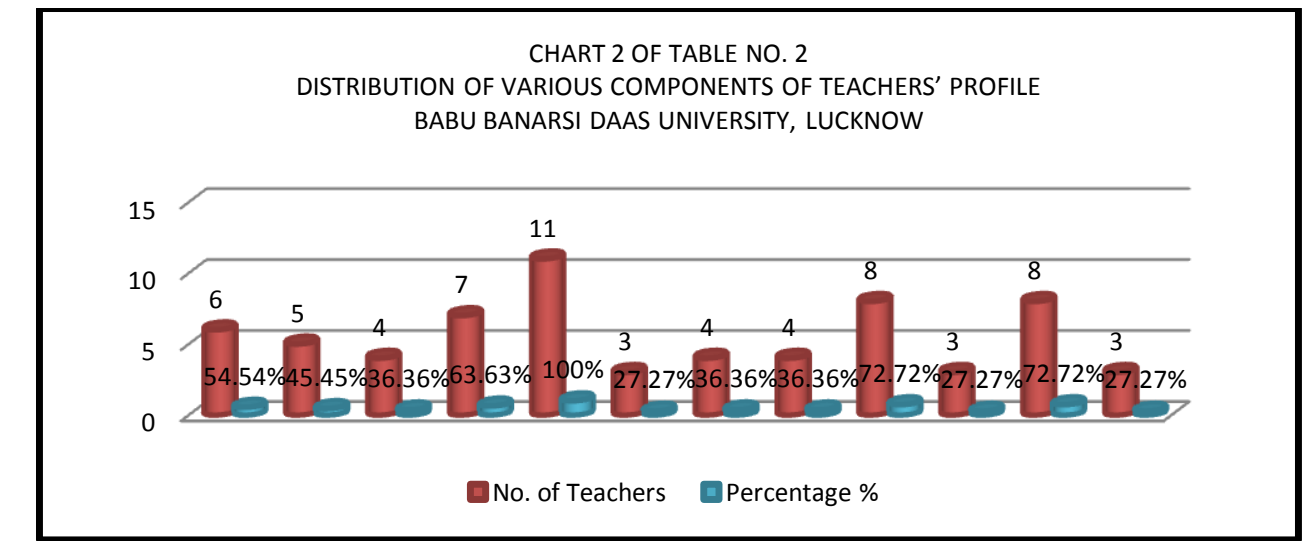

The next table shows the profile of teachers of Karamat Hussain P.G. Girls College, Lucknow. 
TABLE III

Distribution VARIOUS COMPONENTS OF TEACHERS' PROFILE KARAMAT HUSSAIN PG GiRLS COLLEGE, LUCKNOW

\begin{tabular}{|c|l|l|c|c|}
\hline \multirow{2}{*}{ S.No. } & \multicolumn{2}{|c|}{ Components } & No. of Teachers & Percentage \% \\
\hline \multirow{2}{*}{1} & \multirow{2}{*}{ Gender } & Male & 0 & $0 \%$ \\
\cline { 3 - 5 } & & Female & 7 & $100 \%$ \\
\hline \multirow{2}{*}{2} & \multirow{2}{*}{ Age } & Below 29 & 5 & $71.4 \%$ \\
\cline { 3 - 5 } & & Above 30 & 2 & $28.5 \%$ \\
\hline \multirow{4}{*}{3} & \multirow{4}{*}{ Qualification } & Post Graduate & 7 & $100 \%$ \\
\cline { 3 - 5 } & & Pursuing Ph.D & 2 & $28.5 \%$ \\
\cline { 3 - 5 } & Ph.D. & 4 & $57.10 \%$ \\
\cline { 3 - 5 } & \multirow{2}{*}{4} & B.Ed/M.Ed. & 1 & $14.2 \%$ \\
\hline \multirow{2}{*}{5} & Below 5 years & 5 & $28.4 \%$ \\
\cline { 3 - 5 } & \multirow{2}{*}{5} & Above 10 years & 2 & $71.4 \%$ \\
\hline \multirow{2}{*}{ Weekly Work Load } & $16-18$ hours & 5 & $28.5 \%$ \\
\cline { 3 - 5 } & & $10-12$ hours & 2 & \\
\hline
\end{tabular}

According to the above table there are 7 female teachers between 28 and 55 years of age. The age wise composition of the sample indicates that $71.4 \%$ of the teachers are below 29 years of age and the remaining $28.5 \%$ teachers are aged above 30 years of age.

All the teachers of this college possess master's degree in English Literature. 4 of them possess Ph.d. degree, 1 of them has M.Ed. degree and 2 other teachers have been pursuing their Ph.D. 05 out of 7 teachers $(71.5 \%)$ have got less than 05 years of their teaching experience at the U.G. level and the remaining 2 teachers $(28.5 \%)$ have got experience of more than 10 years. Depending upon the strength of the college, 5 out of 7 teachers $(71.5 \%)$ have got the maximum work load of 18 to 20 hours per week. The remaining 2 of them (28.5\%) reported that they engage 10 to12 hours per week. The following Chart No.3 shows the various components of teachers' profile, their numbers and percentage $(\%)$.

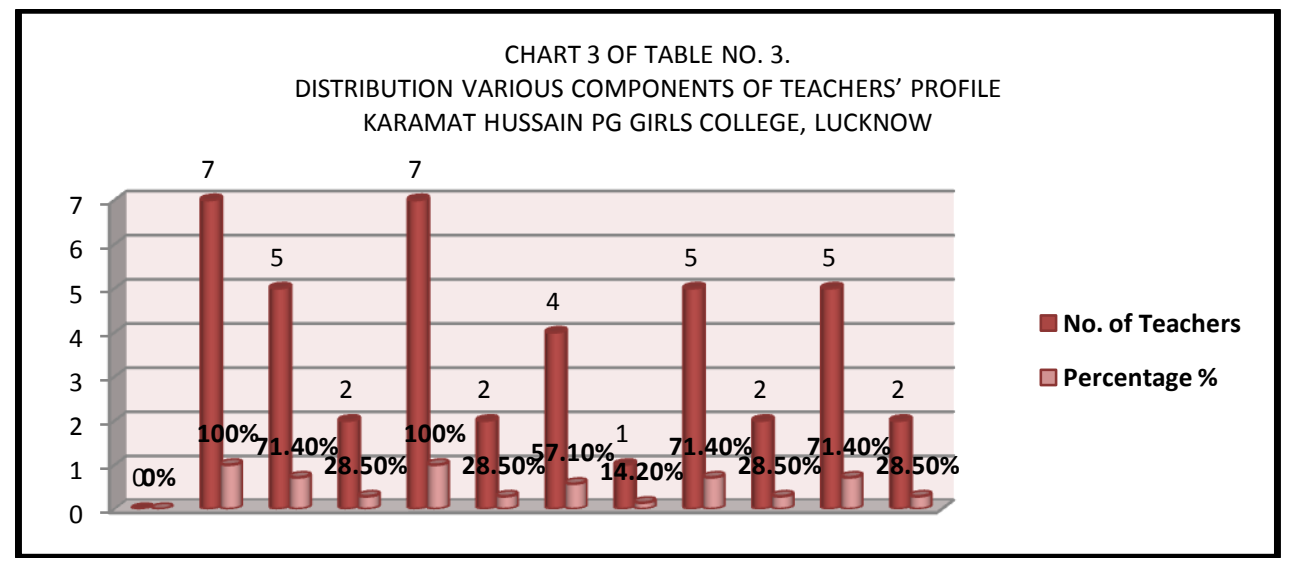

In the same way the sample of the two colleges is further categorized into five different segments on the basis of status, locality, medium of instruction, discipline and the nature and type of the college. The detailed description of the profile of the colleges is displayed in table No.4.

TABLE IV

LIST OF PROFILE OF COLLEGES

\begin{tabular}{|c|c|c|c|c|}
\hline S.No. & \multicolumn{2}{|c|}{ Details } & No. of Colleges & Percentage $\%$ \\
\hline \multirow{2}{*}{1} & \multirow{2}{*}{ Status } & Self Finance & 1 & $50 \%$ \\
\hline & & Grant-in-aid & 1 & $50 \%$ \\
\hline \multirow{2}{*}{2} & \multirow{2}{*}{ Locality } & City & 2 & $100 \%$ \\
\hline & & Town & & $0 \%$ \\
\hline \multirow{2}{*}{3} & \multirow{2}{*}{ Medium of Instructions } & Hindi/Urdu & 1 & $50 \%$ \\
\hline & & English & 1 & $50 \%$ \\
\hline 4 & Discipline & Intermediate & 2 & $100 \%$ \\
\hline \multirow{2}{*}{5} & \multirow{2}{*}{ Type of College } & Co-education & 1 & $50 \%$ \\
\hline & & Women's College & 1 & $50 \%$ \\
\hline
\end{tabular}

The following Chart No. 4 shows the percentage of the status, locality, medium of instruction, discipline and the nature and type of the college. 


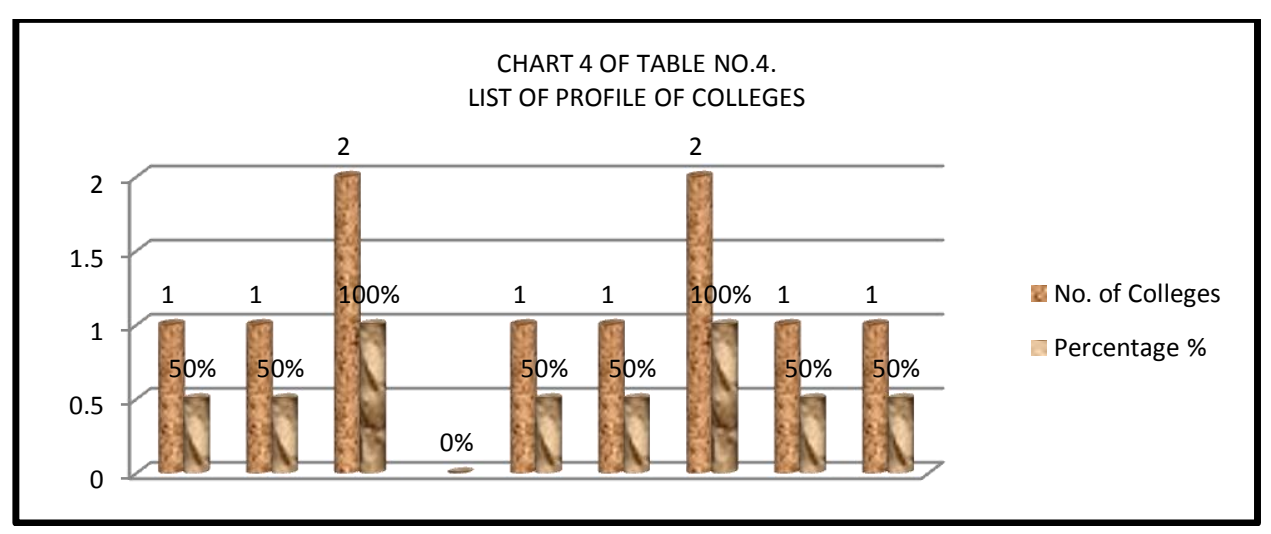

Out of the two colleges under study, one college is English medium; one is Hindi/Urdu medium college in Lucknow division. One college is situated in city area, while the other is situated in the rural area. Accordingly both colleges provide same courses such as Engineering, BBA and BCA. Both the colleges have common English text book for each course.

The qualitative analysis of all the 40 items pertaining to the following aspects of teaching-learning components in English is included in this segment. The components contained questions pertaining to:

* Methodology of Teaching and Teaching practices

* Syllabus designing and

* Examination and Evaluation Methods

\section{B. Data Analysis of Students' Questionnaire}

We had prepared a separate questionnaire for the students to gather the data for analysis of problems faced by students, in teaching and learning process at the intermediate colleges. The questionnaire was divided into six parts. The items of questionnaire Part-1 showed various personal \& academic aspects of the informants. Part-II acquires information regarding the importance of English, mother tongue, schooling and family information of the students. Part III asked questions about "What do informants think about English?" Part IV discussed "how often the informants use English in different places" Part V covered the problems of four English Language skills, and Part VI sheds light on various aspects of importance of English in India.

We have maintained a personal record sheet to collect various personal and other details of the students'. The informants under study were requested to fill-in the personal record pro forma before taking the test. The personal record pro forma provided various personal details such as the gender, mother-tongue, place of schooling, medium of instruction, study of English subject and so on. All the details are given below in the tabular form:

TABLE V

TABLE SHOWING DistRIBUTION OF STUDENTS DETAILS By VARIOUS COMPONENTS

\begin{tabular}{|c|c|c|c|c|}
\hline S.No. & & Components & $\begin{array}{c}\text { No. of } \\
\text { Students }\end{array}$ & Percent $\%$ \\
\hline \multirow{3}{*}{1} & \multirow{3}{*}{ Class } & Engg & 75 & 70.1 \\
\hline & & $\mathrm{BCA}$ & 32 & 29.9 \\
\hline & & Total & 107 & 100.0 \\
\hline \multirow{3}{*}{2} & \multirow{3}{*}{ Gender } & Male & 40 & 37.3 \\
\hline & & Female & 67 & 62.7 \\
\hline & & Total & 107 & 100.0 \\
\hline \multirow{3}{*}{3} & \multirow{3}{*}{ College/Univ. } & BBDU & 63 & 58.8 \\
\hline & & Karamat Husain College & 44 & 41.2 \\
\hline & & Total & 107 & 100.0 \\
\hline \multirow{3}{*}{4} & \multirow{3}{*}{ Age } & $20-24$ & 70 & 65.4 \\
\hline & & $25-30$ & 37 & 34.6 \\
\hline & & Total & 107 & 100.0 \\
\hline \multirow{3}{*}{5} & \multirow{3}{*}{ Place } & Urban & 80 & 74.7 \\
\hline & & Rural & 27 & 25.3 \\
\hline & & Total & 107 & 100.0 \\
\hline
\end{tabular}

The above table shows the consolidated data of the informants. All these information were discussed separately in respective segments. The following Chart No.5 shows the diagrammatical analysis of the above table. 


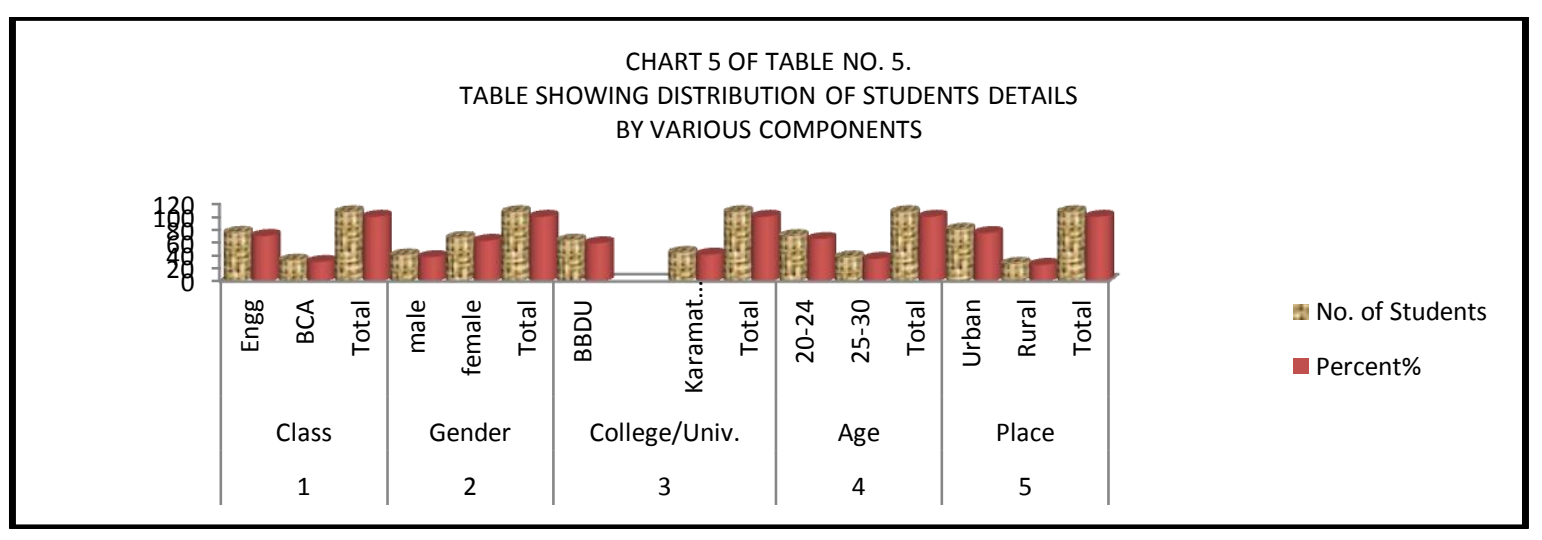

The above table and Chart state the consolidated data of the informants' personal details.

The questions and possible responses in the questionnaire were stated in a manner assumable to rapid, unambiguous coding and processing. We have shown here only part I and part V of the questionnaire as examples. The other parts of the questionnaire were not shown to avoid the length of the paper. See the following charts.

TABLE VI

SHOWING Distribution OF STUdENTS RESPONSE REGARDing THE USE OF ENGLISH.

\begin{tabular}{|c|c|c|c|c|c|c|c|c|c|c|c|c|c|c|c|c|}
\hline & 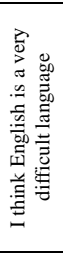 & 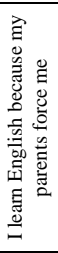 & 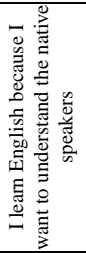 & 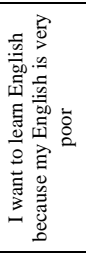 & 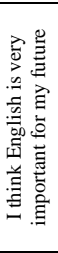 & 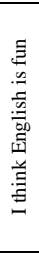 & 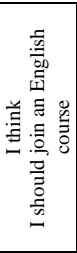 & 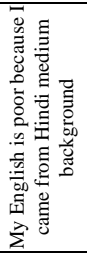 & 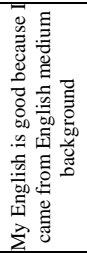 & 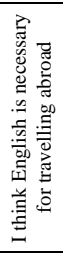 & 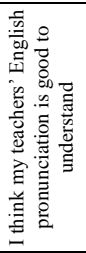 & 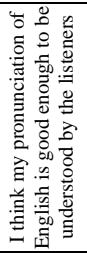 & 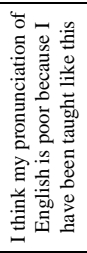 & 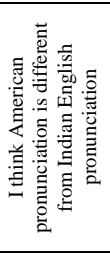 & 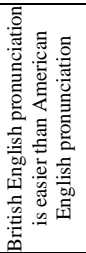 & 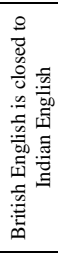 \\
\hline $\begin{array}{l}\text { Strongly } \\
\text { disagree }\end{array}$ & 18 & 52 & 0 & 2 & 0 & 4 & 0 & 13 & 14 & 0 & 1 & 1 & 12 & 2 & 14 & 9 \\
\hline $\begin{array}{c}\text { Disagre } \\
\mathrm{e}\end{array}$ & 54 & 47 & 19 & 29 & 1 & 26 & 29 & 38 & 35 & 1 & 1 & 3 & 47 & 15 & 24 & 21 \\
\hline $\begin{array}{c}\text { Neither } \\
\text { Agree } \\
\text { nor } \\
\text { Disagre } \\
\text { e }\end{array}$ & 24 & 0 & 5 & 10 & 0 & 19 & 17 & 1 & 1 & 23 & 0 & 32 & 28 & 16 & 38 & 19 \\
\hline Agree & 9 & 0 & 65 & 47 & 48 & 16 & 37 & 44 & 45 & 60 & 83 & 51 & 20 & 57 & 20 & 45 \\
\hline $\begin{array}{l}\text { Strongly } \\
\text { agree }\end{array}$ & 2 & 8 & 18 & 19 & 58 & 42 & 24 & 11 & 12 & 23 & 22 & 20 & 0 & 17 & 11 & 13 \\
\hline Total & 107 & 107 & 107 & 107 & 107 & 107 & 107 & 107 & 107 & 107 & 107 & 107 & 107 & 107 & 107 & 107 \\
\hline
\end{tabular}

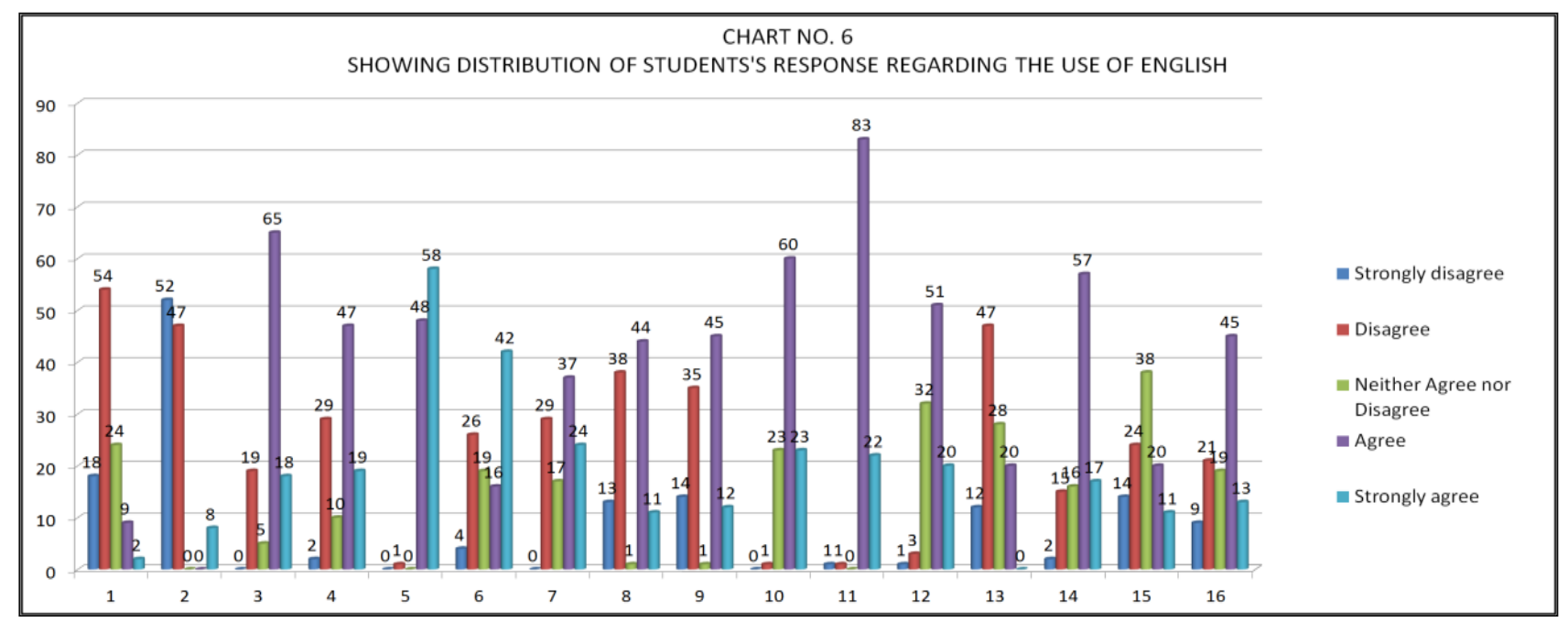

The consolidated data of the informants' was shown in the above table and chart. The responses of the informants were discussed discretely in respective segments viz. problems related to the use of English, thinking about English, why English is poor or good, British English or American English, etc. 54\% students mentioned that English is not very difficult for them. $47 \%$ students reported that their parents do not force them to learn English. $65 \%$ agreed that they learn English because their English is very poor. 83\% students mentioned that their teachers' pronunciation is good to understand. $44 \%$ of them reported that their English is poor because they came from Hindi background while $45 \%$ mentioned that their English is good because they belong to English medium schools. 57\% students reported that 
American English is difficult than British English on the other hand 20\% of them say British English is easier than American English and $45 \%$ agreed that British English is very close to Indian English.

The following table mentions the data of the informants' related to the difficulties they face in different domains of English, viz. Listening \& Speaking, Pronunciation, Grammar, Spelling \& Vocabulary, Writing etc. All these details were discussed separately.

TABLE VII

SHOWs THE RESPONSES OF THE INFORMANTS REGARDING THE LANGUAGE SKILLS, PRONUNCIATION, \& GRAMMAR

\begin{tabular}{|c|c|c|c|c|}
\hline 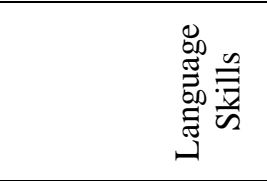 & 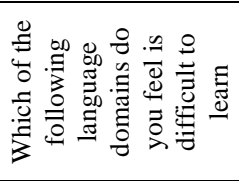 & 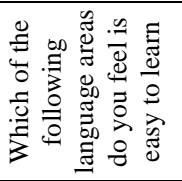 & 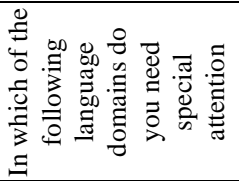 & 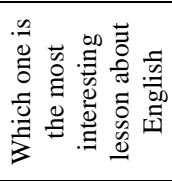 \\
\hline Listening \& Speaking & 22 & 20 & 5 & 25 \\
\hline Pronunciation & 10 & 12 & 51 & 23 \\
\hline Grammar & 10 & 55 & 10 & 20 \\
\hline Spelling \& Vocabulary & 17 & 6 & 21 & 14 \\
\hline Writing & 48 & 14 & 20 & 25 \\
\hline
\end{tabular}

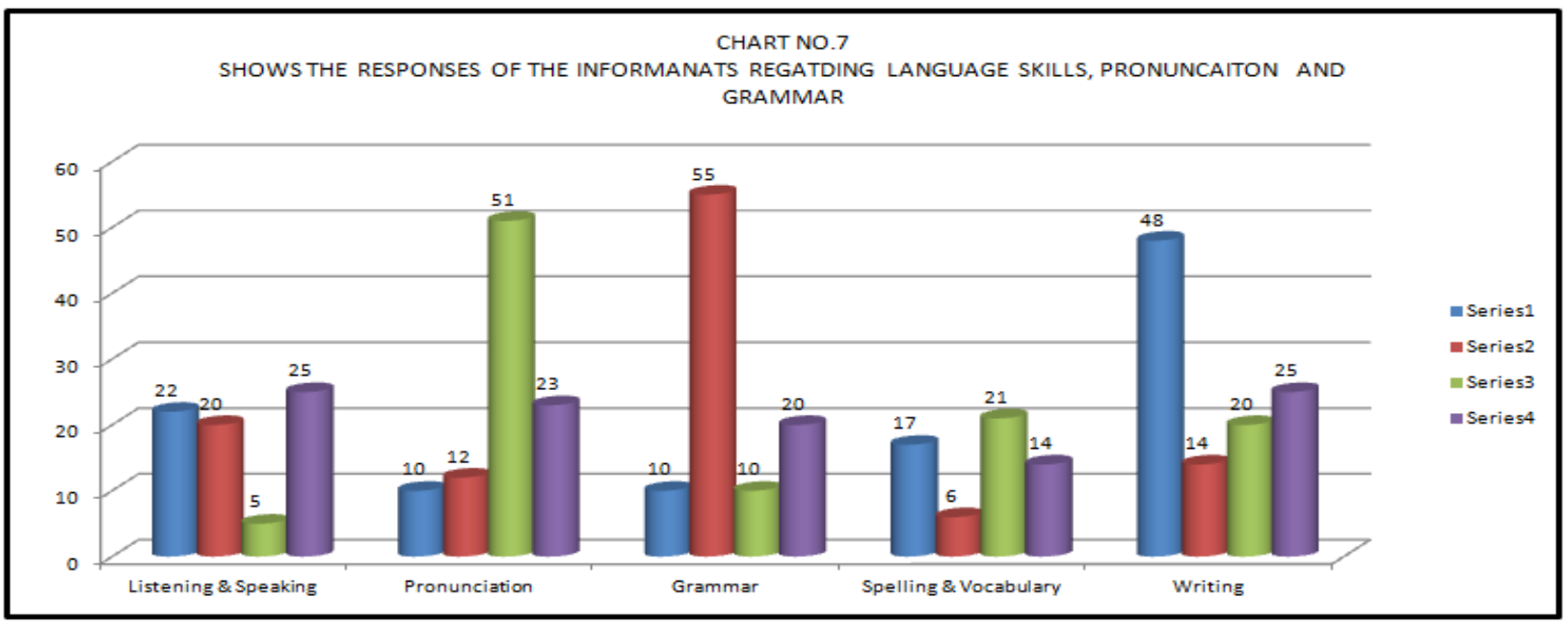

The consolidated data regarding language skills of the informants' is highlighted in the above table and chart. The responses of the informants were discussed separately. $22 \%$ students mentioned that listening and speaking is difficult for them, $20 \%$ reported that listening \& speaking is easy while only $5 \%$ of them need special attention in this domain and $25 \%$ of them say that it is very interesting for them. $10 \%$ students reported that pronunciation is difficult for them, $12 \%$ said that it is easy while around $51 \%$ of them need special attention in this area and $23 \%$ of them feel pronunciation very interesting for them. As far as grammar is concerned 10\% students mentioned that Grammar is difficult for them, 55\% reported that it is easy for them while other $10 \%$ need special attention in this domain and $20 \%$ reported that it is a very interesting subject. Spelling \& Vocabulary is difficult for $17 \%$ students on the other hand only 6 reported it difficult while $21 \%$ students need special attention in this subject and $14 \%$ said that it is a very interesting area. Writing is more difficult than speaking that is why around $48 \%$ students reported that Writing is difficult for them while $14 \%$ mentioned it easy for them. $20 \%$ said that they need special attention and $25 \%$ felt that writing is an interesting subject.

Some students considered English as a tough subject and they had mentioned that as they lacked proper foundation at school level, they face difficulty in grasping the language in the right context while other mentioned that the regional medium of instruction at the school level was one of the reasons for the poor foundation of their language efficiency. On the other hand some students reported about their problem of poor comprehensive ability so that they could not grasp the context of their lessons due to their poor level of vocabulary. Some of them face problems during their examinations particularly while attempting long questions. Others reported that the heterogeneous nature of their class influences their interactive abilities negatively.

\section{FINDINGS}

It was stated by many sample teachers that the present system of lecturing did not give adequate extent for mounting communicative and comprehensive abilities of the students. It has been mentioned by the number of teachers that they go to their classes with their text books and start reading from the book and tell the meaning and difficult part of the text in their mother tongue, we can say that they use grammar translation method. It was also observed that some other teachers adopted the direct method, taught English through the medium of English to heterogeneous group of students in each and every class. Thus, the style and the methodology of teaching varied from teacher to teacher and from 
college to college. Those teachers, who adopted the grammar translation method, used regional language to the maximum extent. It was noted that these methods would not help the students to learn communicative skills. So, the present system which did not emphasize on the development of all the four language skills was found to be totally examination oriented and teacher centered. Hence, this faulty method of teaching was also considered as a problem which poses some difficulties for the students. Many other findings have also indicated the need to change traditional lecturing style and recommended various other techniques and methods to promote better learning language abilities.

All the respondents discussed this issue and their discussions concluded with the following suggestions. The focus should be shifted from the teachers to the students. It is true that good teachers are more valuable than good methods of teaching. The teachers' skills of application of those aspects would matter in the class room teaching-learning process. So, the teacher should choose appropriate style and method to do justification to their teaching.

\section{CONCLUSION AND REMEDIAL MEASURES}

The study is to find out some remedial measures to minimize the ELT problems; we analyzed each and every problem during the course of data analysis of the test results and questionnaires given to the students and teachers. The investigation has concluded with the following remedial measures, suggestions and recommendations.

It was suggested that all the teachers should be encouraged to follow CLT approach in their classes.

* The syllabus designers should measure the suitability of the text books and their relevancy in accordance with the teaching methods, examination and evaluation system.

* The teacher should use role play technique for teaching presentation and spoken English.

* English words should be pronounced with the correct stress patterns.

* Teachers should also take their students to banks, offices, to teach them situational conversations practically.

* Oral approaches, situational teaching, audio lingual approach, communicative language teaching, which emphasize on all the aspects of skills should be implemented in the class room.

* The learners should be encouraged to develop reading habits in order to minimize their pronunciation problem.

* Need based language courses which improve the teachers' efficiency and promote efficient ELT should be executed.

* Special remedial classes should be arranged for weak learners.

* All the colleges should be encouraged to modify the curriculum to cater to the needs of the students.

* Workshops and Seminars should be arranged from time to time for teachers.

* It was also recommended that the students should always be encouraged to participate in talk shows and debates.

* The teacher should teach students how to present their views and compare them with others.

* The teachers should pay full concentration on designing interesting lesson plan which may help to motivate the students.

We ended our discussion with a reference that a teacher of English should keep in mind that he has to select his teaching methodology for a specific group of students according to the level of the students. However, to give equal importance to instruction and practice in all the components of the language will be wasteful and may create confusion. The teacher has to select his priority for a particular teaching period where a relatively greater emphasis would be given to the teaching of a particular component. A skillful and trained teacher can, no doubt, handle an integrative teaching methodology which will ward off the monotony which, after sometime, creeps into a largely drill-dominated instructional period. It also gives an impetus to the motivational factors among the learners.

Whatever the methodology, the teacher should constantly keep in view the importance of English Language Skills. If he/she has considerably reduced the errors normally made by the students, half of the battle with regard to the teaching English to non-native speakers will be won automatically. The teaching of English will be useful only to make the students aware of the suggestions mentioned in the research.

In the present study we have relied for the substantiation of our observations mostly through examples taken from the actual utterances of the students. We have tried to induct the methodology and techniques discussed in this research for improvement. It is needless to emphasize the validity of the fact that language is product of culture. We can say that one has learnt a foreign language only when he has been acculturated in the target language. In other words, the learner has to imbibe in his speech-habits the cultural nuances of the foreign language before he can claim to have learnt the language. The experience of students' competence after twelve years of their schooling in an environment of 'immersion' in the foreign language environment is not very encouraging in the context of the Indian family and social life. The learner, returning home from the foreign language situation, reverts to the use of his/her mother tongue. In certain neo-rich and so-called high society the use of the foreign language in homes is very often ridiculed as artificial and conceited.

The above statement should not be misconstrued as an aspersion on any class of people in India. What we want to bring home is that as we teach the English language without reference to the cultural context, we cannot do the same with the teaching, which have heavily built-in cultural implications. This is because without acquiring the skill of using the basic things he will be misunderstood in his interactional contact not only with the native speakers but also with those in his own country. This is why we have concentrated, in our study, on only the four language skills, vocabulary 
and grammar. As we have mentioned that the study has a pedagogical angle and is proposed to be of utilitarian value. Hence, the discussion of the theoretical aspects has been kept at the minimum level.

\section{REFERENCES}

[1] Arnab, Chaudhary and Jayanta, Mete. (2017). A Study on English Teaching Learning Method in a Hindi Medium School in Nadia District of West Bengal. International Journal of Advanced Research and Development. 2(6), 486-89.

[2] Bloomfield. (1963). Language. Delhi: Motilal Banarsidas.

[3] G. Vijay. (2014). Constraints of Teaching English in Engineering Colleges. Language in India. 14(12), 1-7.

[4] Kothari Commission Report. (1964). New Delhi: Government of India.

[5] Maninder, Kaur K. and Mahesh, Kumar. (2014). Teaching English Language at Engineering and Technology Institutes in India: Problems and Remedies. International Journal of English and Literature. 4(2), 15-21.

[6] Maratab Ali, et.al. (2015). The Pronunciation Difficulties of Urdu Speakers Learning British Accent. International Journal of Research in Management, 2(5), 36-47.

[7] Priya, Sasidharan. (2012). A Need Based Approach To Teaching And Learning Of English For Engineering Purposes. National Institute Of Technology Rourkela. Orissa India.

[8] Qudsiya Iqbal, H. (2016) A Study of the Difficulties in Learning of English Faced by Hindi and Urdu Speaking Students in India and Indian Expatriates in Saudi Arabia." An International Journal of Education. 8(4), 29-46.

[9] Robert, L. (1957) Linguistics across Culture. USA: Ann Arbor-The University of Michigan Press.

[10] Shruti, Pal. (2018). Mother Tongue Influence on Spoken English. Central Institute of Education India ICT for language learning. International Conference: "ITC for Language Learning" 6th Edition.

[11] William Dharma, R. and Selvi, K. (2011). Causes of Problems in Learning English as a Second Language as Perceived by Higher Secondary Students.” I-Managers Journal on English language Teaching. 1(4), 40-45.

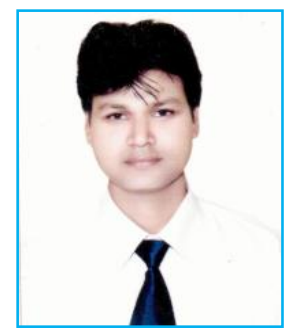

Mohammad Owais Khan was born in Aligarh, Uttar Pradesh, India in 1964. He received his B.A., M.A., and Ph.D degrees in English from Aligarh Muslim University, Aligarh, India, in 1995, 1997 and 2008, respectively. He has done PGCTE (Post Graduate Certificate Course in Teaching English) from EFLU (The English and Foreign Languages University) Hyderabad, India in 1999.

In 2001, he joined the Department of English, Aligarh Muslim University, Aligarh, U.P., India as a Lecturer, and in 2009 he joined the Department of English, College of Languages, Najran University, Najran, Kingdom of Saudi Arabia as an Assistant Professor. His field of specialization is ELT (English Language Teaching) particularly (ESL/EFL) Second/Foreign Language and Applied Linguistics. His area of interest is Applied Linguistics, Teaching Language through Literature, Phonetics and Phonology, Curriculum and Syllabus Designing. He is a member of the Department and Research Council, College of Languages, Najran University. 